This is the peer reviewed version of the paper:

Filipović, S., Obradović, N., Marković, S., Mitrić, M., Balać, I., Đorđević, A., Pavlović, V.B., 2019. The effect of ball milling on properties of sintered manganese-doped alumina. Advanced Powder Technology 30, 2533-2540.

https://doi.org/10.1016/j.apt.2019.07.033

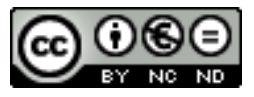

This work is licensed under a Creative Commons Attribution Non Commercial No Derivatives 4.0 license 


\title{
The effect of ball milling on properties of sintered manganese-doped alumina
}

\author{
S. Filipović ${ }^{1, *}$, N. Obradović ${ }^{1}$, S. Marković ${ }^{1}$, M. Mitrić ${ }^{2}$, \\ I. Balać ${ }^{3}$, A. Đorđević ${ }^{4,5}$, V. Pavlović ${ }^{1}$ \\ ${ }^{1}$ Institute of Technical Sciences of the Serbian Academy of Sciences and Arts, 11000 Belgrade, \\ Serbia \\ 2 “Vinča” Institute of Nuclear Sciences, University of Belgrade, 11000 Belgrade, Serbia \\ ${ }^{3}$ Faculty of Mechanical Engineering, University of Belgrade, 11000 Belgrade, Serbia \\ ${ }^{4}$ School of Electrical Engineering, University of Belgrade, 11000 Belgrade, Serbia \\ ${ }^{5}$ Serbian Academy of Sciences and Arts, 11000 Belgrade, Serbia
}

\begin{abstract}
Alumina-based compounds have many technological applications and attract great attention even after decades of investigation, due to their good chemical, electrical, and mechanical properties. A mixture of several alumina modifications $\left(\alpha-, \kappa-, \gamma-\mathrm{Al}_{2} \mathrm{O}_{3}\right)$ doped with 1 wt. $\%$ of $\mathrm{Mn}_{2} \mathrm{O}_{3}$ was used for this experiment. The powder was mechanically activated for 60 minutes in an ethanol medium. After compaction, green bodies were sintered in the temperature range from 1200 to $1400{ }^{\circ} \mathrm{C}$. Microstructures of the obtained specimens were investigated by scanning electron microscopy (SEM) and Energy-dispersive X-ray spectroscopy (EDS). The influence of morphological changes on electrical and mechanical properties was examined in detail. We have developed a test fixture and corresponding software for measurement of the relative dielectric permittivity and the loss tangent of ceramic specimens. This new method overcomes the problems of dimensions and shape of samples, as well as the problem of applying silver paste. The accuracy is around $2 \%$ for $\varepsilon_{\mathrm{r}}^{\prime}$ and 0.003 for $\tan \delta$. We demonstrate that the mechanical activation (MA) has the dominant influence on lowering the characteristic temperatures and microstructure development, which further leads to increased permittivity and tensile strength.
\end{abstract}

Keywords: Alumina; Ceramics; Sintering; Properties

*Corresponding author: Tel.: +381112027203

E-mail address: suzana.filipovic@itn.sanu.ac.rs (Dr. Suzana Filipović)

Declarations of interest: none 


\section{Introduction}

Alumina is one of the most commonly used ceramic materials for various applications owing to its specific physical, chemical, optical, electrical, and mechanical properties. $\alpha$-alumina possesses high chemical stability and hardness owing to its strong ionic bonds [1,2]. Due to its good characteristics, alumina has a wide range of applications. As a dense ceramic material, alumina is used in electronics for production of high-temperature electrical insulators [1], for armor system [3], etc. Also, porous alumina ceramic has a wide range of applications in catalysis and as a filter for water purification $[4,5]$.

Doping of alumina has been extensively studied. It was shown that even a small amount of dopants, such as $\mathrm{MgO}$, accelerates the sintering process and densification of alumina [6-8]. This was explained by changes in grain surface, which lead to increase in surface and grain boundaries diffusion. It was established that $\mathrm{Mn}^{+2}$ lowers the reaction temperature. Particularly, addition of manganese oxide shifts the temperature of transition from $\gamma$ - to $\alpha$ - alumina [9, 10]. It was demonstrated earlier that addition of manganese oxide accelerate densification for numerous ceramics, such as ceria, zirconia, yttria-stabilized zirconia, etc. [11-13]. The increased densification was explained by the grain boundary mobility caused by changes in the valence state of manganese and oxygen vacancies formation.

The transformation of transition alumina phases into the most stable $\alpha$-alumina occurs through several steps during heating [14]. The phase transformation into $\alpha$-alumina goes through the formation of nuclei. The low-density nucleation structure creates dendrite-like grains surrounded by continuous pore channels, demanding high temperatures $\left(>1600{ }^{\circ} \mathrm{C}\right)$ for obtaining dense ceramics. Preparation conditions play a significant role in decreasing the sintering temperature and elimination of pores. Therefore, the investigation of adequate preparation conditions is still a hot research topic $[15,16]$. The MA has a significant influence on modification of the active surface of the powder through a large number of plastic deformations, introducing a large number of defects into the crystal lattice of powder particles, which is mostly reflected through changes in diffractogram patterns of the activated powders. The level of structural disordering is mainly determined by the duration of the mechanical treatment, used ball-to-powder ratio, speed of rotation of the vessel, etc. [17-19]. The increase in the active surface and the number of particles in the mechanically activated powders favors the formation of intergranular contacts. The mass transport is the main process that enables sintering and densification, through different transport mechanisms, such as grain boundary diffusion, surface diffusion, etc. The enlarged number of formed contact necks in activated powders facilitates sintering and densification through 
an increased flux of atoms coming to the necks, leading to the decrease of the sintering temperature along with the decrease of temperatures of formation of intermedial and/or final products [20].

The major disadvantage of the mechanical activation, as a way for obtaining sub-micrometer and/or nanoscaled materials, is the formation of agglomerates. The agglomerates suppress the sinterability and densification by lowering the number of contacts among particles and impeding the mass transport, which is a driving force for the sintering process. For that purpose, the soft mechanochemistry, i.e., milling in wet media, is frequently used [21].

The microstructure has the dominant influence on the ceramic properties after sintering. The evolution of the microstructure and its impact on the mechanical and electrical properties is of a great interest for fundamental and applied sciences. It was shown that the density and grain size has the major influence on the relative permittivity, while impurities dominantly affect the loss tangent [22-24].

Various electrical parameters of insulating materials (dielectrics) are important in the research and development in electrical engineering. Our major focus is on the relative permittivity and the corresponding loss tangent, as well as their variation with frequency. We measured these parameters using our improved method, suitable for small ceramic samples.

In this paper, the influence of MA in wet media on the microstructure development of the doped and sintered alumina ceramic was investigated. The obtained dielectric permittivity and loss tangent were related to the microstructure of the doped and sintered alumina ceramics.

\section{Experimental procedures}

Powders were prepared by doping of the initial alumina powder with $1 \mathrm{wt} \%$ of $\mathrm{Mn}_{2} \mathrm{O}_{3}$ (all $99 \%$ purity, Sigma-Aldrich) and MA in a planetary ball mill, as presented in our previous work [25]. The milling process was performed in $\mathrm{ZrO}_{2}$ vial with $\mathrm{ZrO}_{2}$ balls in ethanol media. The first charge was only homogenized, by milling for one minute, and the second charge was milled for 60 minutes. According to the preparation conditions, powders were labeled as AM1 (homogenized powder) and AM60 (milled for 60 minutes). The initial alumina powder contains few phases $(\alpha-, \kappa-$, $\gamma$-, and $\mathrm{Al}(\mathrm{OH})_{3}$ ), which was confirmed by the X-ray powder diffraction (XRD) analysis.

The influence of the MA on the particle size distributions was investigated by the laser diffraction on Mastersizer 2000 Malvern Instruments Ltd. (particle size analysis - PSA), where the powders were dispersed in distilled water. The used instrument covers the particle size range of 0.02-2000 $\mu \mathrm{m}$. Changes in the powder morphology were investigated by SEM and EDS (on JEOL JSM-6390 LV scanning electron microscope, coupled with EDS Oxford Instruments X-MaxN; powders were covered with gold in order to perform these techniques). 
Simultaneous differential thermal analysis (DTA) and thermogravimetric analysis (TGA) were performed on the instrument Setsys (SETARAM Instrumentation, Caluire, France) in the temperature range between the room temperature and $1400{ }^{\circ} \mathrm{C}$, under the air flow of $20 \mathrm{ml} \mathrm{min}^{-1}$, in an $\mathrm{Al}_{2} \mathrm{O}_{3}$ pan. The heating rate was $10{ }^{\circ} \mathrm{C} \mathrm{min}^{-1}$.

Milled samples were pressed under an uniaxial pressure of $98 \mathrm{MPa}$. Thus prepared green bodies were subjected to the sintering process in the tube furnace Protherm (PTF 16/75/450) in the temperature range $1200-1400{ }^{\circ} \mathrm{C}$ in an air atmosphere, at a heating rate of $10{ }^{\circ} \mathrm{C} \mathrm{min}-1$ and dwell time of $2 \mathrm{~h}$ on the maximal reached temperature. The obtained samples were labeled as AM1-1200, AM1-1300, AM1-1400, AM60-1200, AM60-1300, and AM60-1400, according to the applied sintering temperature. All sintered specimens were examined in detail.

XRD was performed in order to determine the phase composition. Measurements were done on Philips PW-1050 diffractometer with $\lambda \mathrm{Cu}-\mathrm{K} \alpha$ radiation in an air atmosphere and at the room temperature. The diffractometer was used with $\mathrm{Cu}-\mathrm{K} \alpha$ radiation and a step/time scan mode of $0.05^{\circ} \mathrm{s}^{-1}$ in the $2 \theta$ range $10-80^{\circ}$. The scanning electron microscopy of the sintered samples was performed on cracked samples covered by gold on the same instrument as the powders.

For measurement of the relative dielectric permittivity (dielectric constant) and the loss tangent of the sintered specimens, we have designed and manufactured a test fixture and developed dedicated software, as described in section 3.1.

The tensile strength of the prepared samples was determined by the Brazilian test [26]. This test is frequently used for the evaluation of the tensile strength of materials such as concrete, rock, and ceramic materials, as it was explained in our previous paper [25].

\section{Methods}

\subsection{Measurement of dielectric properties}

Fig. 1 shows the cross-section of the test fixture that we have developed for measurement of dielectric parameters of ceramic materials at frequencies in the $\mathrm{MHz}$ range. It is an improved version of our fixture described previously [27]. Measurements up to several hundred megahertz are predominantly based on the measurement of the capacitance of a parallel-plate capacitor, where the sample is inserted between the electrodes of the capacitor. During preparation for the measurements, there may form small air gaps and pockets between the sample and the electrodes, which reduce the accuracy of the method for high-permittivity materials. A remedy may be to metallize the bases of the sample, e.g., by silver painting, which is not always an easy task. Another problem is that for such samples the electromagnetic fields in the sample and the measurement 
structure cannot be assumed to be quasistatic already at about $100 \mathrm{MHz}$, which imposes problems on the extraction of the dielectric parameters. Further, at higher frequencies, internal resonances may occur in the sample and jeopardize the measurement accuracy.

The reflection coefficient at the SMA connector of the chamber is measured using an Agilent E5061A vector network analyzer (VNA). From this coefficient, the input complex admittance of the chamber is calculated using numerical electromagnetic models.

\section{2. Measurement of mechanical properties}

The Brazilian test [26] was used to determine the tensile strength of the prepared specimens. In this test, a disc-shaped specimen is inserted between two punches, where the lower punch is kept fixed, while the upper punch is moveable and the compression load is applied to it. The load is slowly increased until failure occurs. Formula for calculating the tensile strength $\sigma_{\mathrm{t}}$ (MPa) based on the Brazilian test is (ASTM D 3967):

$$
\sigma_{t}=\frac{2 P}{\pi D t}
$$

where $P$ is the load at failure $(\mathrm{N}), D$ is the diameter of the test specimen $(\mathrm{mm})$, and $t$ is the thickness of the test specimen measured at the center $(\mathrm{mm})$.

A revised formula for calculating the tensile strength was proposed by $\mathrm{Yu}$ et al. [28]:

$$
\sigma_{t}=\frac{(1+0.2621 k) 2 P}{\pi D t}
$$

where $k$ is the ratio of the thickness to the diameter $(t / D)$ of the disc specimen.

\section{Results and discussion}

In our experiment, a mixture of several alumina modifications $\left(\alpha-, \kappa-, \gamma-\right.$, and $\left.\mathrm{Al}(\mathrm{OH})_{3}\right)$ was used as the starting powder, which is confirmed by XRD diffractograms shown in Fig. 2. All observed peaks were identified by adequate ICDD cards, which are listed in [25]. Also, a remarkable level of disordering of alumina was noticed in the starting mixture along with a welldefined crystalline structure of manganese oxide (sharp and intense peaks of $\mathrm{Mn}_{2} \mathrm{O}_{3}$ ). After the mechanical treatment, broadening was noticed along with a decrease of intensities for all detected reflections, indicating a reduction in the average crystallite size and introduction of a high concentration of defects into the crystal lattice [20]. There were no new peaks detected in the 
diffractogram of the activated powder, confirming that mechanochemical reaction does not occur during milling.

The reduction in grain size, influenced by treating the powder in a high energy ball mill, could be verified by monitoring changes in particle size distribution, shown in Fig. 3.

From Fig. 3 it can be noticed that the non-activated sample (AM1) shows a bimodal distribution, due to the non-homogeneous mixture, with the dominant presence of particles around $1.6 \mu \mathrm{m}$. Further, the existence of agglomerates whose size is approximately $10 \mu \mathrm{m}$ was observed. After 60 minutes of milling, agglomerates were destructed, and the distribution was narrower. The measured span was decreased from 4.64 to $2.72 \mu \mathrm{m}$. The main effect of the MA is in the equalization of the particle sizes, which can be concluded by comparing the values of $d(0.1), d(0.5)$, and $\mathrm{d}(0.9)$. The most pronounced decrease was detected for $\mathrm{d}(0.9)$, from $12.69 \mu \mathrm{m}$ to $7.21 \mu \mathrm{m}$, proving the destruction of large agglomerates.

Changes in the powder morphology after milling were established by the scanning electron microscopy. As it was explained earlier in the text, huge agglomerates were crushed by the mechanical treatment. Single particles in the range $200-400 \mathrm{~nm}$ were detected along with smaller agglomerates, of size larger than $2 \mu \mathrm{m}$. Also, it can be seen from micrographs that particles dominantly have the tendency to associate into bigger clusters, Fig. 4.

Thermal analyses (DTA and TGA) were used to establish the thermal behavior of these powders. For the non-activated powder (AM1, Fig. 5 a), three endothermic peaks were observed. The first one at $94{ }^{\circ} \mathrm{C}$ corresponds to water evaporation and was followed by a mass loss of around $3 \%$. The second small endothermic peak at $250{ }^{\circ} \mathrm{C}$ probably originated from dehydroxylation of gibbsite $\mathrm{Al}(\mathrm{OH})_{3}[29,30]$, whose presence was confirmed by XRD (see Fig. 2). The third endothermic peak detected at $963{ }^{\circ} \mathrm{C}$ comes from formation of cubic spinel, $\mathrm{Mn}_{2} \mathrm{AlO}_{4}$, which occurs at around $950{ }^{\circ} \mathrm{C}$ according to the literature data [31, 32]. In the DTA curve of the activated sample (AM60, Fig. 5 b), all the above mentioned peaks were detected. The first and the second peak in the activated sample were less pronounced. This proves that the heat developed during the mechanical treatment initiates the observed processes. Further, the third peak, originated from spinel formation, is shifted toward lower temperatures, indicating the existence of more active grains surfaces, densely packed particles, and a facilitated reaction. Further, the small broad exothermic peak, at $1067{ }^{\circ} \mathrm{C}$, can be noticed in the DTA curve, but in TG or dTG (inlay images in Fig. 5.) there is no mass loss. In this temperature range, the phase transformation of aluminum oxide $(\gamma \rightarrow \alpha)$ usually occurs [33-35].

After compacting and sintering the non-activated and activated powders at 1200, 1300, and $1400{ }^{\circ} \mathrm{C}$, XRD patterns were recorded. Fig. 6 a) and b) present diffractograms of all sintered ceramic specimens. All detected reflections were identified by ICDD cards (PDF2- 71-1683 for $\alpha$ - 
$\mathrm{Al}_{2} \mathrm{O}_{3}$, PDF2- 29-0881 for $\mathrm{Mn}_{2} \mathrm{AlO}_{4}$, and PDF2- 02-0464 for $\mathrm{ZrO}_{2}$ ). After sintering, the $\alpha-\mathrm{Al}_{2} \mathrm{O}_{3}$ phase dominates in all samples. In the non-activated sintered samples there is also a small amount of the spinel phase $\mathrm{Mn}_{2} \mathrm{AlO}_{4}$. That amount is larger within the activated sintered samples. This is due to a more intense contact between particles and significantly increased active surfaces in the activated samples. In the samples AM60-1200, AM60-1300, and AM60-1400 traces of the $\mathrm{ZrO}_{2}$ phase were detected due to milling in a zirconium oxide vessel and with zirconium oxide balls. All reflections are sharp and intensive, indicating a fully crystalline structure.

The microstructure of the starting powders has a significant influence on the morphology development in the final sintered bodies. Changes in the particle size and shape due to the milling lead to changes in the sinterability and the final structure. For the samples AM1-1200, AM1-1300, and AM1-1400, the main characteristic is that they are in an early sintering stage; with a high volume of open porosity in the range 55-40\% (see Table 1), as a consequence of the sintering of agglomerated powders, which is confirmed by PSA and SEM of the starting powder (Fig. 3 and Fig. 4 a). Also, in the non-activated samples, the Mn-rich parts are not homogeneously distributed, but rather localized in certain regions, shown as red areas in EDS pictures (the right parts of Fig. 7 a-c).

The contribution of the MA in a wet medium, as pretreatment in ceramic preparation, was easily noticed in the microstructures of the samples AM60-1200, AM60-1300, and AM60-1400 (Fig. 8). It was proposed by other authors that decreasing the particle size in starting powders can significantly increase the sintering rate, which is in a good correlation with the microstructures of the activated and sintered specimens presented in Fig. 8. The absence of huge agglomerates and decreasing the particle size, after milling in alcohol, were confirmed by PSA and EDS of powders (Fig. 3 and 4). This justifies usage of a wet medium during mechanical activation.

The micrographs of the activated sintered samples (Fig. 8) indicate the intermediate sintering stage in AM60-1200 and AM60-1300, and the beginning of the final sintering stage in AM60-1400. The porosity decreases compared to the non-activated sintered samples, reaching $10 \%$ for AM60-1400. AM60-1400 shows the most compact structure with blocks of well sintered material. Destruction of agglomerates by milling for 60 minutes facilitates the mass transport and promotes densification. In the activated and sintered specimens, Mn-rich regions are scattered through the volume in spite of the longer milling process and the more homogenized initial powder used for obtaining these samples (see EDS photographs in Fig. 8). The obtained low densities are probably a consequence of the low applied pressure during compaction of powders (98 MPa) and low sintering temperatures. However, benefits of the mechanical activation on the structure, densification, and sintering are clearly evident. 
Fig. 9 shows the measured real part of the relative permittivity $\left(\varepsilon_{\mathrm{r}}^{\prime}\right)$ and the loss tangent ( $\tan \delta$ ), as a function of frequency, for all specimens, measured and calculated by using our new chamber. The real part of the relative permittivity decreases with frequency. This decay can be explained by considering the causality conditions for the complex permittivity [36].

The density and the porosity have the dominant influence on the permittivity and loss tangent of ceramic materials [37]. As shown in Table 1, with increasing the density, the real part of the relative permittivity increases and the loss tangent decreases. It can be noticed that with increasing the sintering temperature, the relative permittivity rises. The denser packing of smaller particles within the activated powder and the higher applied temperatures facilitate sintering, grain growth, and strengthening of grain boundaries. This leads to achievement of higher densities and, consequently, higher relative permittivity. This can be explained by considering ceramic sample as a composite of dielectric and pores, e.g., air, whose permittivity is 1 . With increasing the porosity fraction, more air is trapped into the volume, resulting in a decreased permittivity. It was shown that some models, Looyenga, Bruggeman, Maxwell-Garnett and refractive index, developed from this assumption, fit the experimental data with slight deviation [38].

The relative permittivity of pure alumina is between 7 and 9 [39]. The addition of manganese oxide decreases the permittivity, which is observed in literature [40]. This can be useful for application as insulators for certain high-frequency applications, in microelectronics, etc.

Table 1. Measured mass, dimensions, density, porosity, real part of relative permittivity, and loss tangent (at $200 \mathrm{MHz}$ ).

\begin{tabular}{|l|c|c|c|c|c|c|c|c|}
\hline Sample & $\boldsymbol{m} \mathbf{( g )}$ & $\boldsymbol{D}(\mathbf{m m})$ & $\boldsymbol{t}(\mathbf{m m})$ & $\begin{array}{c}\boldsymbol{\rho} \\
\left(\mathbf{g} / \mathbf{c m}^{\mathbf{3}}\right)\end{array}$ & $\begin{array}{c}\boldsymbol{\rho}_{\text {rel }} \\
(\mathbf{\% T D})\end{array}$ & $\boldsymbol{\Pi} \mathbf{( \% )}$ & $\varepsilon_{\mathrm{r}}^{\prime}$ & $\tan \delta$ \\
\hline AM1-1200 & $0.3788 \pm 0.0001$ & $9.585 \pm 0.001$ & $3.105 \pm 0.001$ & 1.692 & 45.720 & 54.281 & $3.12 \pm 0.06$ & $0.058 \pm 0.003$ \\
\hline AM60-1200 & $0.3775 \pm 0.0001$ & $9.335 \pm 0.001$ & $3.030 \pm 0.001$ & 1.821 & 49.224 & 50.776 & $4.58 \pm 0.09$ & $0.042 \pm 0.003$ \\
\hline AM1-1300 & $0.3779 \pm 0.0001$ & $8.779 \pm 0.001$ & $2.832 \pm 0.001$ & 2.206 & 59.611 & 40.389 & $3.35 \pm 0.07$ & $0.051 \pm 0.003$ \\
\hline AM60-1300 & $0.3685 \pm 0.0001$ & $8.992 \pm 0.001$ & $2.319 \pm 0.001$ & 2.504 & 67.662 & 32.338 & $4.87 \pm 0.1$ & $0.022 \pm 0.003$ \\
\hline AM1-1400 & $0.3682 \pm 0.0001$ & $8.465 \pm 0.001$ & $2.236 \pm 0.001$ & 2.927 & 79.119 & 20.881 & $4.18 \pm 0.09$ & $0.033 \pm 0.003$ \\
\hline AM60-1400 & $0.3692 \pm 0.0001$ & $8.035 \pm 0.001$ & $2.180 \pm 0.001$ & 3.342 & 90.326 & 9.684 & $5.89 \pm 0.1$ & $0.016 \pm 0.003$ \\
\hline
\end{tabular}

The tensile strength of the prepared samples was determined by Equation 2 after performing the Brazilian test. The aspect ratio $k$ for each specimen was calculated from the data for the diameter $(D)$ and thickness $(t)$ given in Table 1 . The obtained results for the load at failure $(P)$, the aspect ratio, and the calculated tensile strength $\left(\sigma_{t}\right)$ are presented in Table 2. The crushed specimen, shown in Fig. 2, suggests that the splitting crush of the disc is caused by tensile stresses. 
This fact confirms the validity of the used equation for calculating the tensile strength of the examined specimens (Equation 2) as well as the Brazilian test itself.

Table 2. Load at failure - $\mathrm{P}$, aspect ratio - $k$, and tensile strength $-\boldsymbol{\sigma}_{\mathrm{t}}$, for tested specimens.

\begin{tabular}{|c|c|c|c|}
\hline Sample & $\boldsymbol{P}(\mathbf{N})$ & $\boldsymbol{k}(\mathbf{m m})$ & $\boldsymbol{\sigma}_{\mathrm{t}}(\mathbf{M P a})$ \\
\hline AM1-1200 & 146.67 & 0.323944 & $3.404 \pm 0.851$ \\
\hline AM1-1300 & 240.28 & 0.324585 & $5.868 \pm 1.408$ \\
\hline AM1-1400 & 642.27 & 0.322588 & $17.836 \pm 3.567$ \\
\hline AM60-1200 & 289.07 & 0.257896 & $9.421 \pm 2.355$ \\
\hline AM60-1300 & 1428.55 & 0.264146 & $51.373 \pm 10.240$ \\
\hline AM60-1400 & 3398.25 & 0.271313 & $132.286 \pm 25.080$ \\
\hline
\end{tabular}

Regarding the strength of the tested specimens, it can be concluded that the sample AM60-1400 has a significantly higher tensile strength (132.286 MPa) than the other tested samples. It is evident that all samples exhibit better strength performance after activation for 60 minutes. Such behavior can also be attributed to changes in the microstructure and density. The lower porosity in the material microstructure leads to higher material stiffness and strength, while the irregular shape of pores strongly influences the material fracture toughness and strength. Therefore, the microstructure plays an important role in the mechanical properties of material.

\section{Conclusions}

In this paper, the influence of the MA and sintering at different temperatures on the microstructure, phase composition, physical properties, and tensile strength of alumina doped with manganese oxide was investigated.

It was shown that the MA increased the surface activity of the powder, leading to easier chemical reactions, such as formation of spinel $\mathrm{Mn}_{2} \mathrm{AlO}_{4}$. Also, the temperature of reaction is lowered, as confirmed by thermal analyses. Further, it was demonstrated that the mechanical activation increased the obtained densities from approximately $60 \%$ to $90 \%$ of TD for samples sintered at $1400{ }^{\circ} \mathrm{C}$.

The greatest effect of the MA in wet media was on the morphology evolution. Within the activated powder, $\mathrm{Mn}_{2} \mathrm{O}_{3}$ was more uniformly distributed in the alumina matrix. Agglomerates were crushed and the particle size distribution was narrower, which promotes sintering and densification through increased flux of atoms coming to the necks and increased number of formed contact necks. 
It was shown that the microstructure development has the dominant influence on the electrical and mechanical properties of the sintered ceramics. According to the measured tensile strength, the activated and sintered alumina with the addition of $\mathrm{Mn}_{2} \mathrm{O}_{3}$ exhibits a relatively high resistance to mechanical failure when loaded.

Having in mind that alumina has a wide range of applications, as dense and as porous ceramic materials, the results presented in this paper allow further optimization of the preparation parameters in order to obtain the optimal structure and electrical properties of this type of ceramic material.

\section{Acknowledgements}

This investigation was supported by the Ministry of Education, Science and Technological Development of the Republic of Serbia, and it was conducted under the projects OI 172057 and III 45019.

\section{Data availability}

The raw/processed data required to reproduce these findings cannot be shared at this time due to technical and time limitations.

\section{References}

[1] I. S. A. Farag, I. K. Barrisha, M. M. Ei-Rafaay, Study of dielectric properties of $\alpha$-alumina doped with MnO, CdO and MoO, Indian Journal of Pure \& Applied Physics, 43 (2005) 446-458.

[2] A. G. Tarasov, V. A. Gorshkov, V. I. Yukhvid, Phase composition and microstructure of $\mathrm{Al}_{2} \mathrm{O}_{3}$ $\mathrm{Cr}_{2} \mathrm{O}_{3}$ solid solutions prepared by self-propagating high-temperature synthesis, Inorganic Materials, 43 (2007) 724-728.

[3] M. Scapin, L. Peroni, M. Avalle, Dynamic Brazilian Test for Mechanical Characterization of Ceramic Ballistic Protection. Shock Vibration, 2017 (2017) 1-10.

[4] A. I. Osman, J. K. Abu-Dahrieh, D.W. Rooney, S. A. Halawy, M. A. Mohamed, A. Abdelkader, Effect of precursor on the performance of alumina for the dehydration of methanol to dimethyl ether, Applied Cataliysis B: Enviromental, 127 (2012) 307-315.

[5] R. Zotov, E. Meshcheryakov, A. Livanova, T. Minakova, O. Magaev, L. Isupova, I. Kurzina, Influence of the Composition, Structure, and Physical and Chemical Properties of AluminiumOxide-Based Sorbents on Water Adsorption Ability, Materials, 11 (2018) 132.

[6] S. J. Bennison, M. P. Harmer, Effect of $\mathrm{MgO}$ solute on the kinetics of grain growth in $\mathrm{Al}_{2} \mathrm{O}_{3}$, Journal of the American Ceramic Society, 66 (1983) C90-2. 
[7] K. A. Berry, M. P. Harmer, Effect of $\mathrm{MgO}$ solute on microstructure development in $\mathrm{A}_{2} \mathrm{O}_{3}$. Journal of the American Ceramic Society, 69 (1986) 143-9.

[8] G. G. Long, S. Krueger, R. A. Page, The effect of green density and the role of magnesium oxide additive on the densification of alumina measured by small-angle neutron scattering, Journal of the American Ceramic Society, 74 (1991) 1578-84.

[9] D. Gouvea, R. L. Villalobos, J. D. T. Capocchi, Polymeric Precursor Synthesis of Alumina Containing Manganese Oxide Matererials, Scientific Forum, 299-300 (1999) 91-98.

[10] M. Crisan, M. Rileanu, S. Preda, M. Zaharescu, A. M. Valean, E. J. Popovici, V. S. Teodorescu, V. Matejec, J. Mrazek, Manganese doped sol-gel materials with catalytic properties, Journal of Optoelectronics and advanced Materials, 8 (2006) 815-819.

[11] T. S. Zhang, Z. H. Du, S. Li, L. B. Kong, X. C. Song, J. Lu, J. Ma, Transitional metal-doped 8 mol\% yttria-stabilized zirconia electrolytes, Solid State Ionic, 180 (2009) 1311-1317.

[12] L. Wu, J. A. Aguiar, P. P. Dholabhai, T. Holesinger, T. Aoki, B. P. Uberuaga, R. H. R. Castro, Interface energies of nanocrystalline doped ceria: effects of manganese segregation, The Journal of Physical Chemistry C., 119 (2015) 27855-27864.

[13] H. Li, F. L. Souza, R. H. R. Castro, Kinetic and thermodynamic effects of manganese as a densification aid in yttria-stabilized zirconia, Journal of the European Ceramic Society, 38 (2018) $1750-1759$.

[14] E. Yalamaç, A. Trapani, S. Akkurt, Sintering and microstructural investigation of gammaalpha alumina powders, Engineering Science and Technology, an International Journal 17 (2014) 27.

[15] J. R. Neto, R. Moreno, Effect of mechanical activation on the rheology and casting performance of kaolin/talc/alumina suspensions for manufacturing dense cordierite bodies, Applied Clay Science, 38(3-4) (2008) 209-218.

[16] T. Ebadzadeh, Effect of mechanical activation and microwave heating on synthesis and sintering of nano-structured mullite, Journal of Alloys and Compounds, 489 (2010) 125-129.

[17] M. Kiani, T. Ebadzadeh, Effect of mechanical activation and microwave sintering on crystallization and mechanical strength of cordierite nanograins, Ceramics International, 41 (2015) 2342-2347.

[18] S. Filipović, N. Obradović, D. Kosanović, V.B. Pavlović, A. Đorđević, Sintering of the mechanically activated $\mathrm{MgO}-\mathrm{TiO}_{2}$ system, Journal of Ceramic Processing Research, 14 (2013) 3134.

[19] E. Biazar, A. Beitollahi, S. M. Rezayat, T. Forati, A. Asefnejad, M. Rahimi, et al, Effect of the mechanical activation on size reduction of crystalline acetaminophen drug particles, International Journal of Nanomedicine, 2009 (2009) 283-287. 
[20] S. Filipović, N. Obradović, V. B. Pavlović, M. Mitrić, A. Đorđević, M. Kachlik, et al., Effect of consolidation parameters on structural, microstructural and electrical properties of magnesium titanate ceramics, Ceramics International, 42 (2016) 9887-9898.

[21] N. Obradović, S. Filipović, N. Đorđević, D. Kosanović, V. Pavlović, D. Olćan, A. Đorđević, M. Kachlik, K. Maca, Microstructural and Electrical Properties of Cordierite-based Ceramics Obtained After Two-step Sintering Technique, Science of Sintering, 48 (2016) 157-165.

[22] X. Kuang, X. Jing, Z. Tang, Dielectric loss spectrum of ceramic $\mathrm{MgTiO}_{3}$ investigated by AC impedance and microwave resonator measurements, Journal of the American Ceramic Society, 89 (2006) 241-246.

[23] N. Obradović, S. Filipović, N. Đorđević, D. Kosanović, S. Markovića, V. Pavlović, D. Olćan, A.Djordjević, M. Kachlik, K. Maca, Effects of mechanical activation and two-step sintering on thestructure and electrical properties of cordierite-based ceramics, Ceramics International, 42 (2016) 13909-13918.

[24] S. J. Perm, N. McN. Alford, A. Templeton, X. Wang, M. Xu, M. Reece, K. Schrapelt, Effect of Porosity and Grain Size on the Microwave Dielectric Properties of Sintered Alumina, Journal of the American Ceramic Society, 80 (1997) 1885-1888.

[25] S. Filipović, N. Obradović, S. Marković, A. Đorđević, I. Balać, A. Dapčević, J. Rogan, V. B. Pavlović, Physical Properties of Sintered Alumina Doped with Different Oxides, Science of Sintering, 50 (2018) 409-419.

[26] T. Akazawa, New test method for evaluating internal stress due to compression of concrete: the splitting tension test, Journal of Japan Society Civil Eng, 29 (1943) 777-787.

[27] A. Đorđević, J. Dinkić, M. Stevanović, D. Olćan, S. Filipović, and N. Obradović, Measurement of permittivity of solid and liquid dielectrics in coaxial chambers, Microwave Review, 22 (2016) 3-9.

[28] Y. Yu, J. Yin, Z. Zhong, Shape effects in the Brazilian tensile strength test and a 3D FEM correction, International Journal of Rock Mechanics and Mining Sciences, 43 (2006) 623-627.

[29] D. Redaoui, F. Sahnoune, M. Heraiz, A. Raghdi, Mechanism and Kinetic Parameters of the Thermal Decomposition of Gibbsite $\mathrm{Al}(\mathrm{OH})_{3}$ by Thermogravimetric Analysis, Acta Physica Polonica A, 131 (2017) 562-565.

[30] J. T. Kloprogge, H. D. Ruan, R. L. Frost, Thermal decomposition of bauxite minerals: infrared emission spectroscopy of gibbsite, boehmite and diaspore, Journal of Materials Science, 37 (2002) 1121-1129.

[31] O. A. Bulavchenko, S. V. Tsybulya, S. V. Cherepanova, T. N. Afonasenko, P. G. Tsyrulnikov, High-temperature X-ray study of the formation and delamination of manganese-alumina spinel $\mathrm{Mn}_{1.5} \mathrm{Al}_{1.5} \mathrm{O}_{4}$, Journal of Structural Chemistry, 50 (2009) 474-478. 
[32] R. Krukirnr, S. Tamulevičius, High Temperature Oxidation of Thin Chromel-Alumel Thermocouples, Mater. Sci. (Medžiagotyra) 10 (2004), 136-141.

[33] S. Lamouri, M. Hamidouche, N. Bouaouadja, H. Belhouchet, V. Garnier, G. Fantozzi, et al., Control of the $\gamma$-alumina to $\alpha$-alumina phase transformation for an optimized alumina densification, Boletín de la Sociedad Española de Cerámica y Vidrio, 56 (2017) 47-54.

[34] J. Lee, H. Jeon, D.G. Oh, J. Szanyi, J.H. Kwak, Morphology-dependent phase transformation of $\gamma-\mathrm{Al}_{2} \mathrm{O}_{3}$, Applied Catalysis A: General, 500 (2015) 58-68.

[35] W.M. Shaheen, K.S. Hong, Thermal Characterization and Physico-Chemical Properties of $\mathrm{Fe}_{2} \mathrm{O}_{3}-\mathrm{Mn}_{2} \mathrm{O}_{3} / \mathrm{Al}_{2} \mathrm{O}_{3}$ Systems, Journal of Thermal Analysis and Calorimetry, 68 (2002) 289-306.

[36] A. R. Djordjevic, R. M. Biljic, V. D. Likar-Smiljanic, T. K. Sarkar, Wideband frequencydomain characterization of FR-4 and time-domain causality. IEEE Transactions on Electromagnetic Compatibility, 2001 Nov;43(4):662-667.

[37] X. Kuang, X. Jing, Z. Tang, Dielectric Loss Spectrum of Ceramic $\mathrm{MgTiO}_{3}$ Investigated by AC Impedance and Microwave Resonator Measurements, Journal of American Ceramic Society, 89 (2006) 241-246.

[38] R. Vila, M Gonzalez, J. Molla, A. Ibarra, Dielectric spectroscopy of alumina ceramics over a wide frequency range, Section 4. Physical properties of unirradiated and irradiated ceramics, Journal of Nuclear Materials, 253 (1998) 141-148.

[39] C. Neusel, G.A. Schneider, Size-dependence of the dielectric breakdown strength from nanoto millimeter scale, Journal of the Mechanics and Physics of Solids, 63 (2014) 201-213.

[40] L. U. Cong, Y. Jian, L. Xiao-Yun, Q. Tai, Effect of Chromium and Manganese Co-doping on the Vacuum Voltage-Withstanding Properties of Alumina Ceramics, Journal of Synthetic Crystals 45 (2016) 133-137.

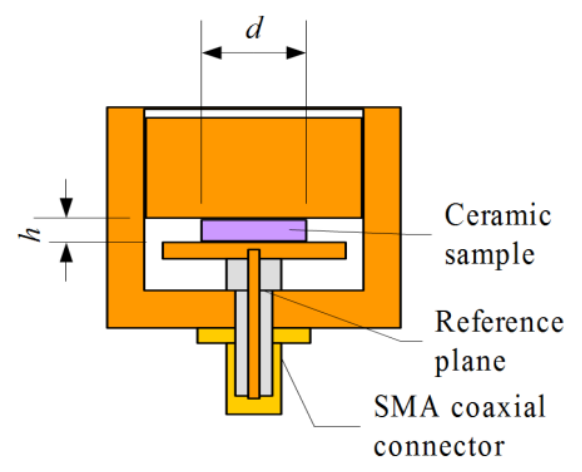

Fig. 1. 


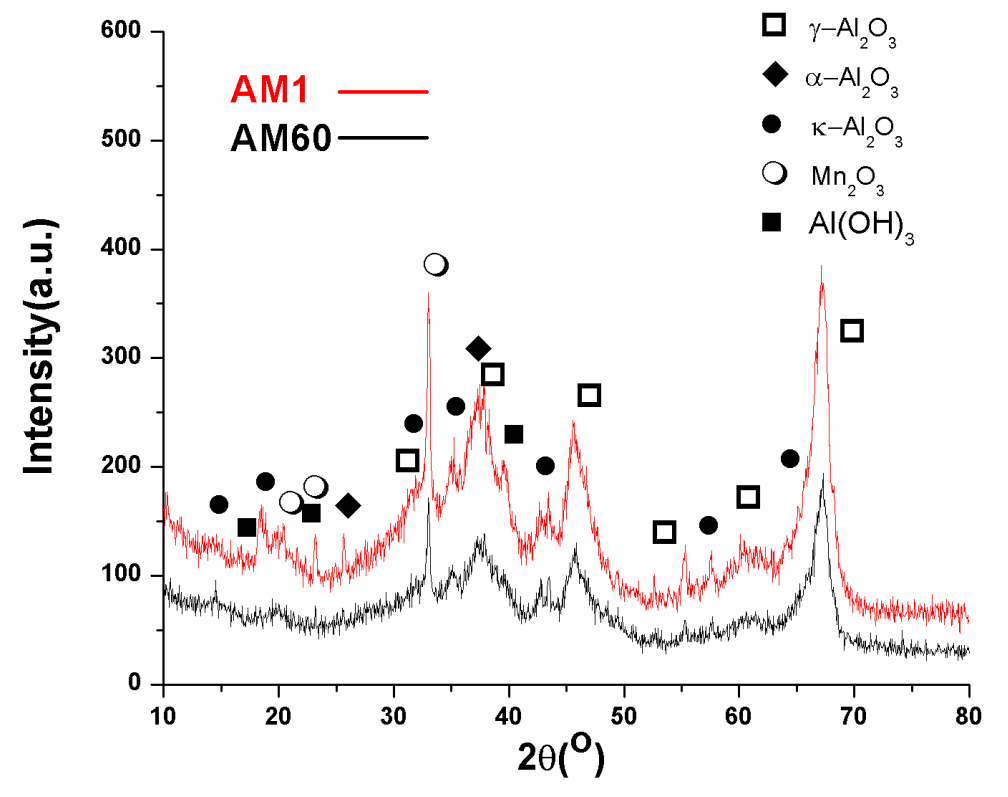

Fig. 2 .

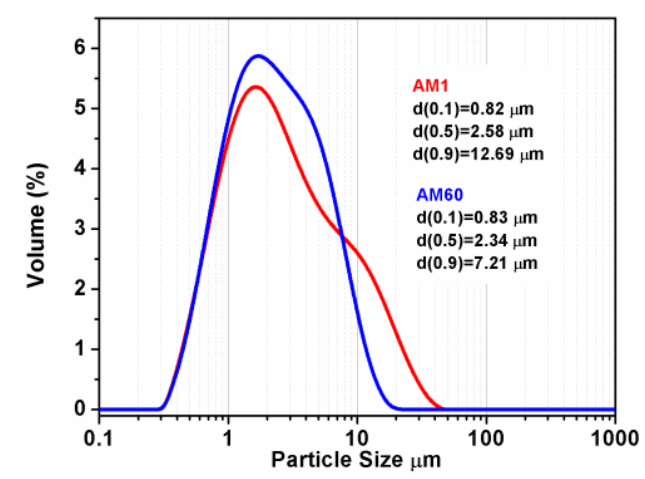

Fig.3. 


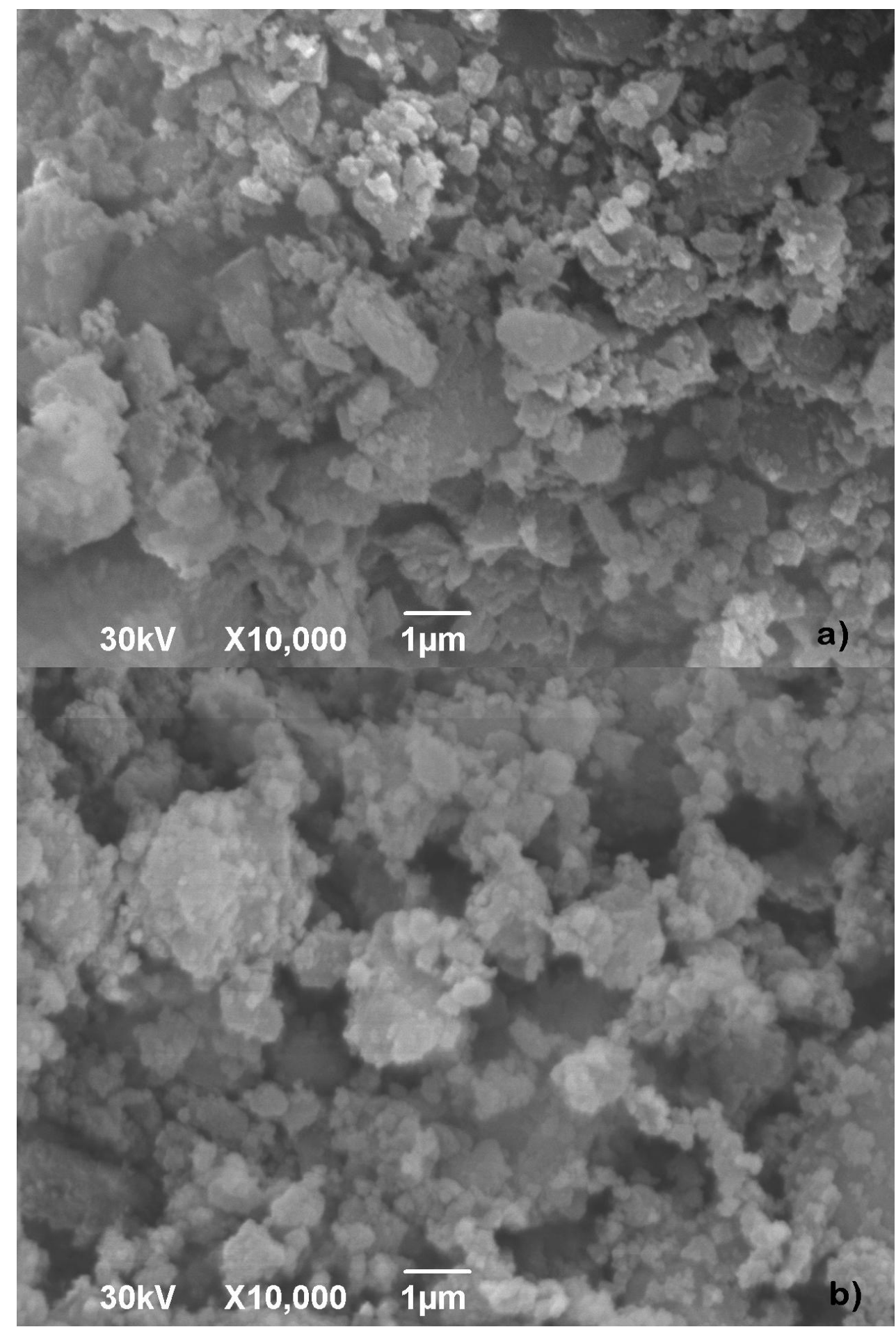

Fig.4. 

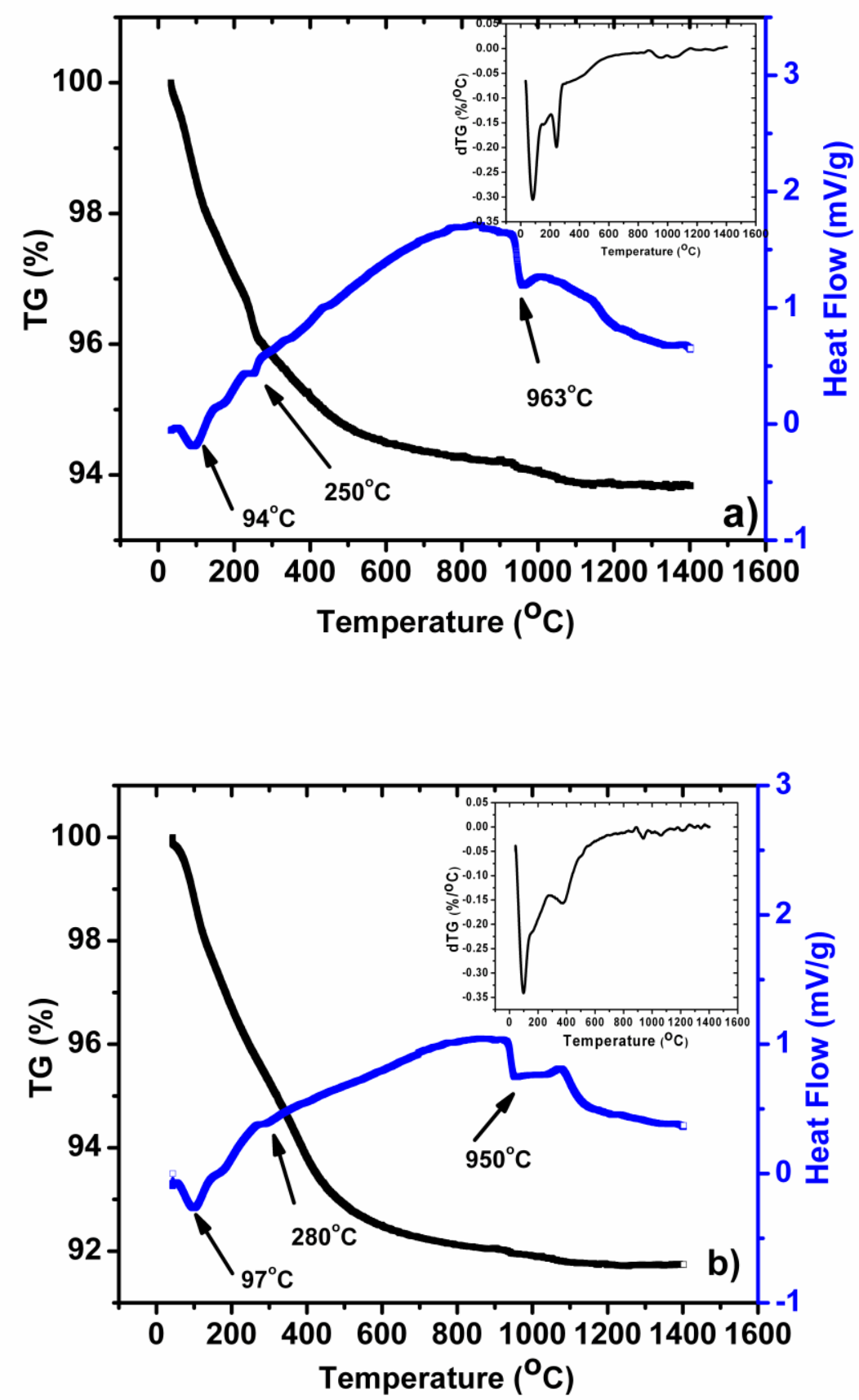

Fig.5.
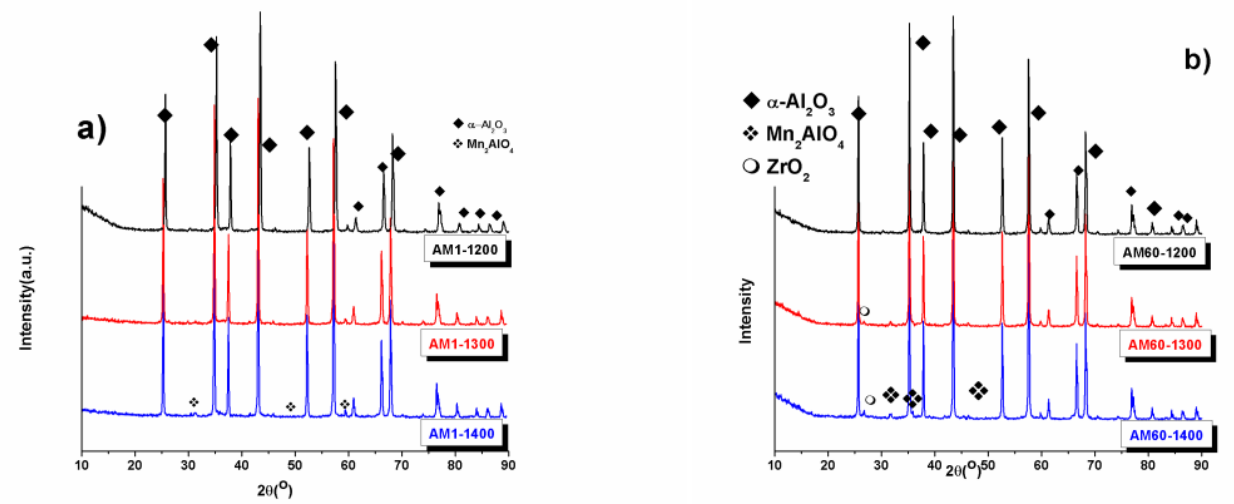

Fig.6. 

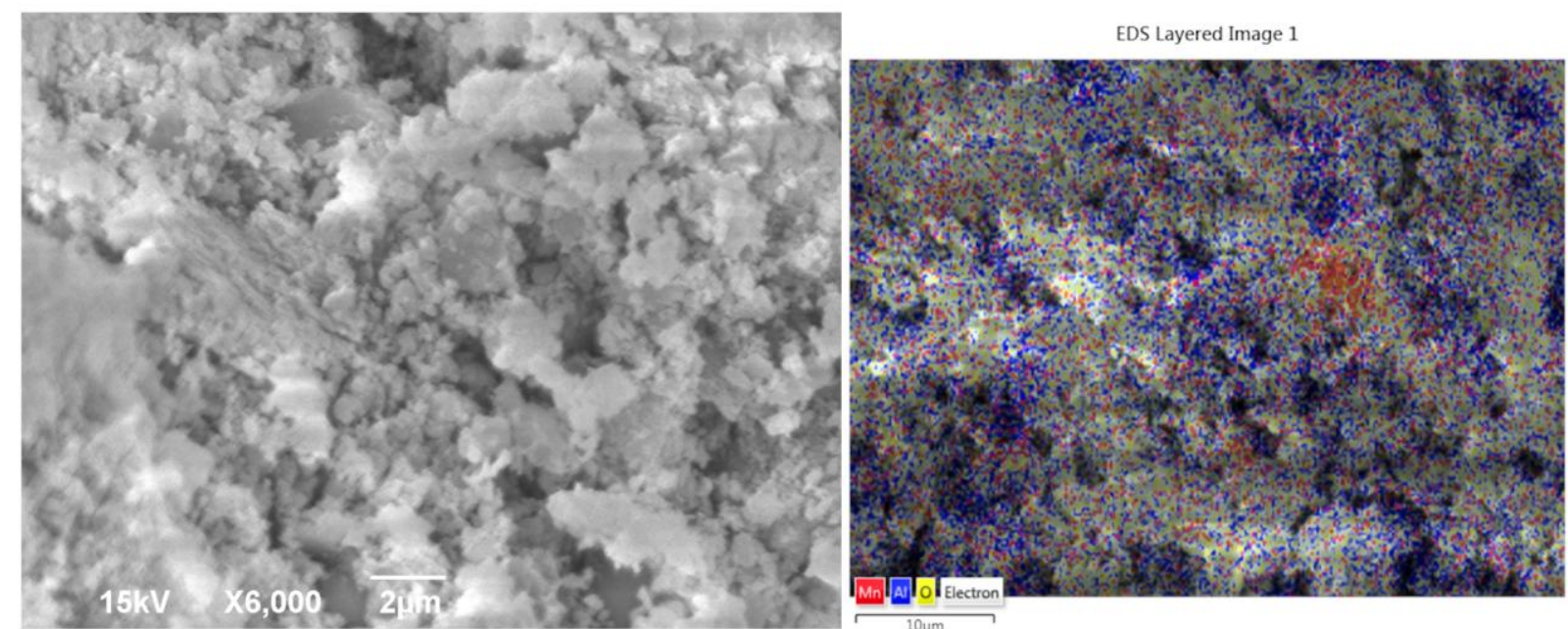

Fig.7.a
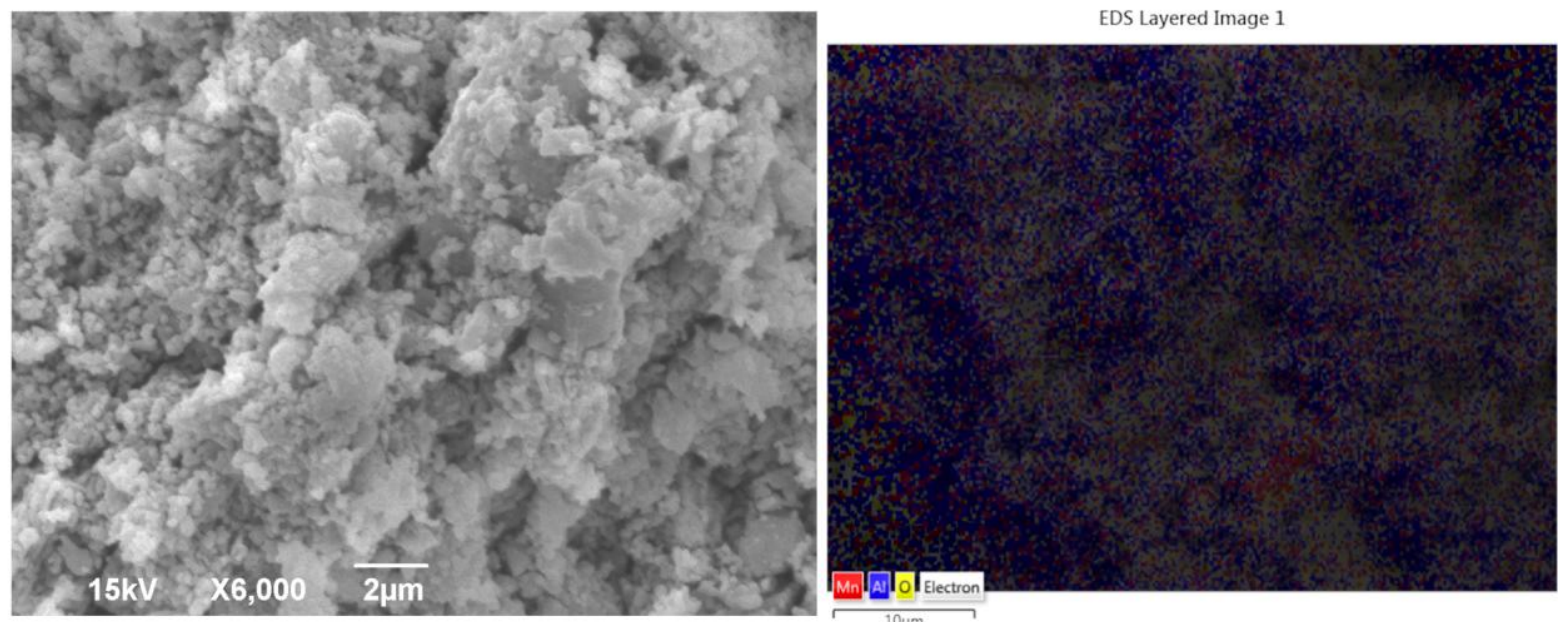

Fig.7.b

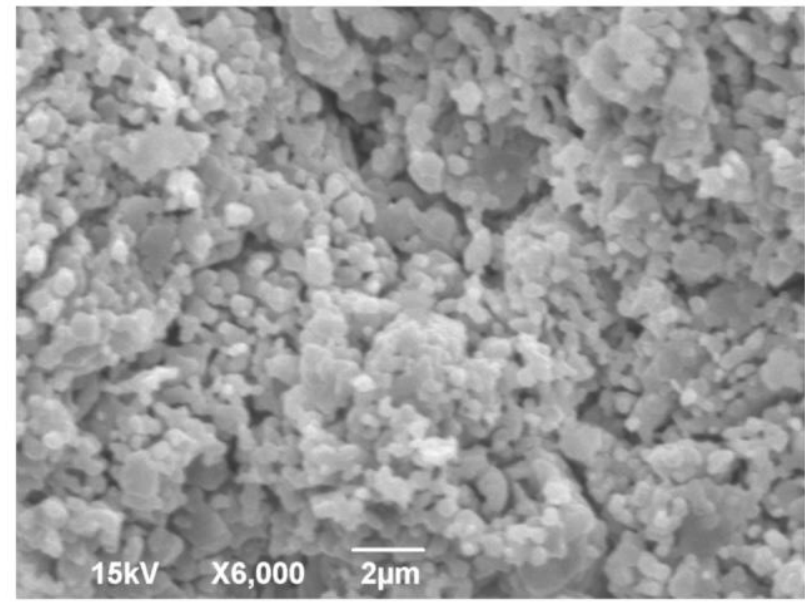

EDS Layered Image 1

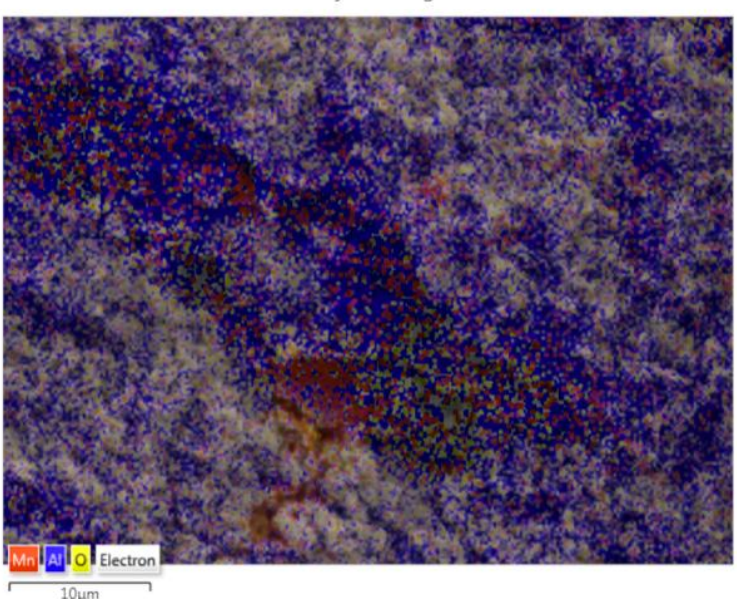

Fig.7.c 

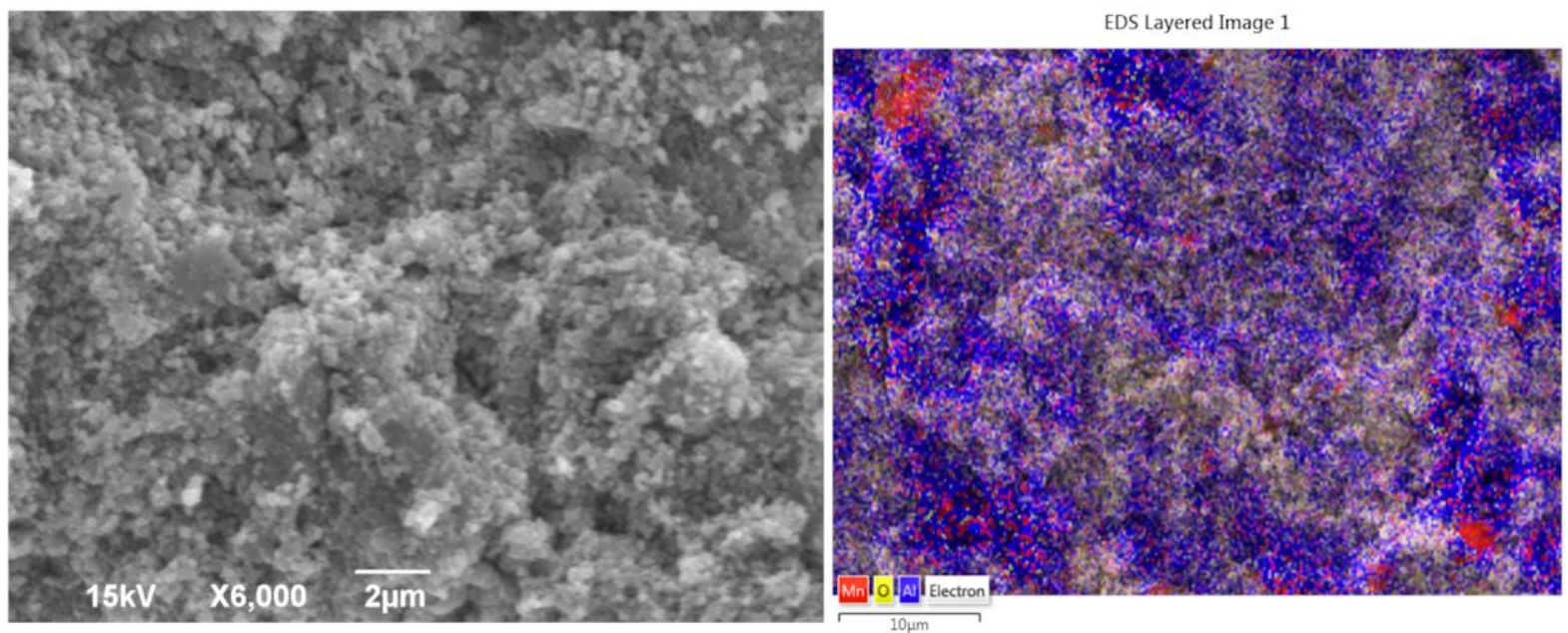

Fig.8.a
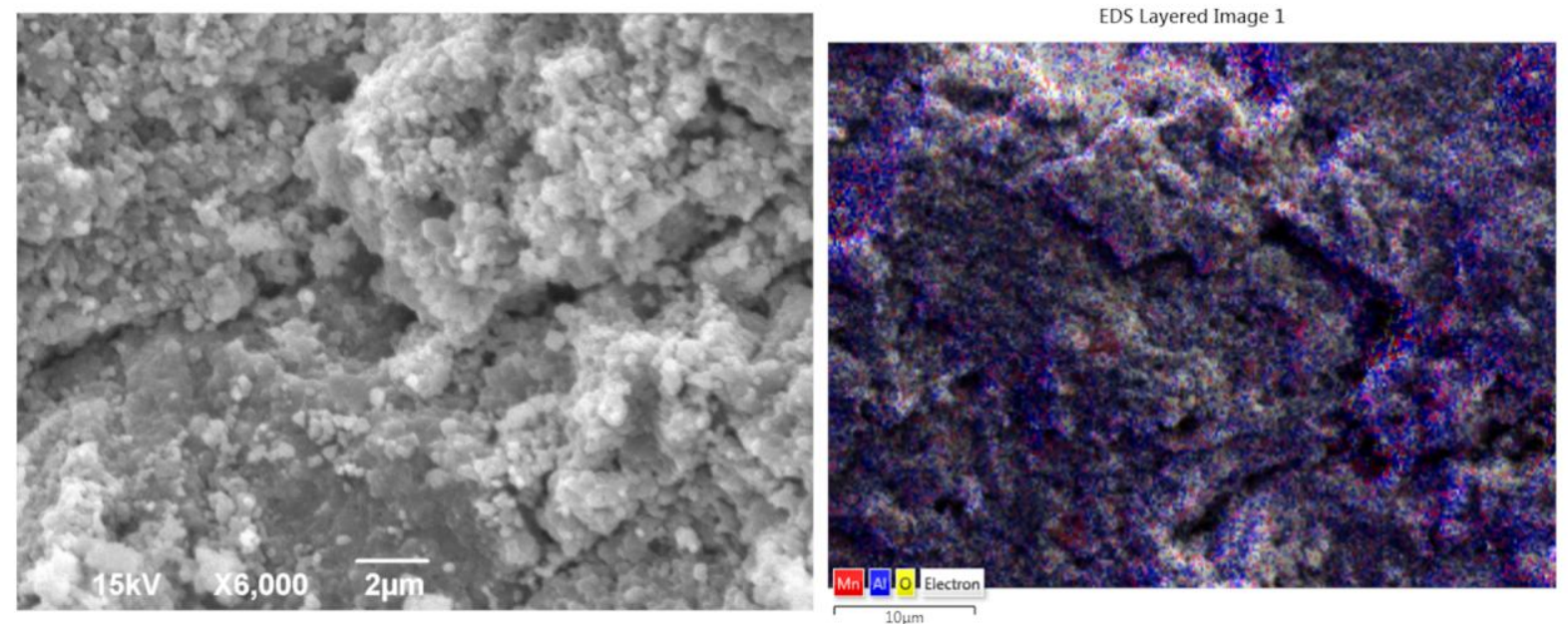

Fig.8.b

EDS Layered Image 1

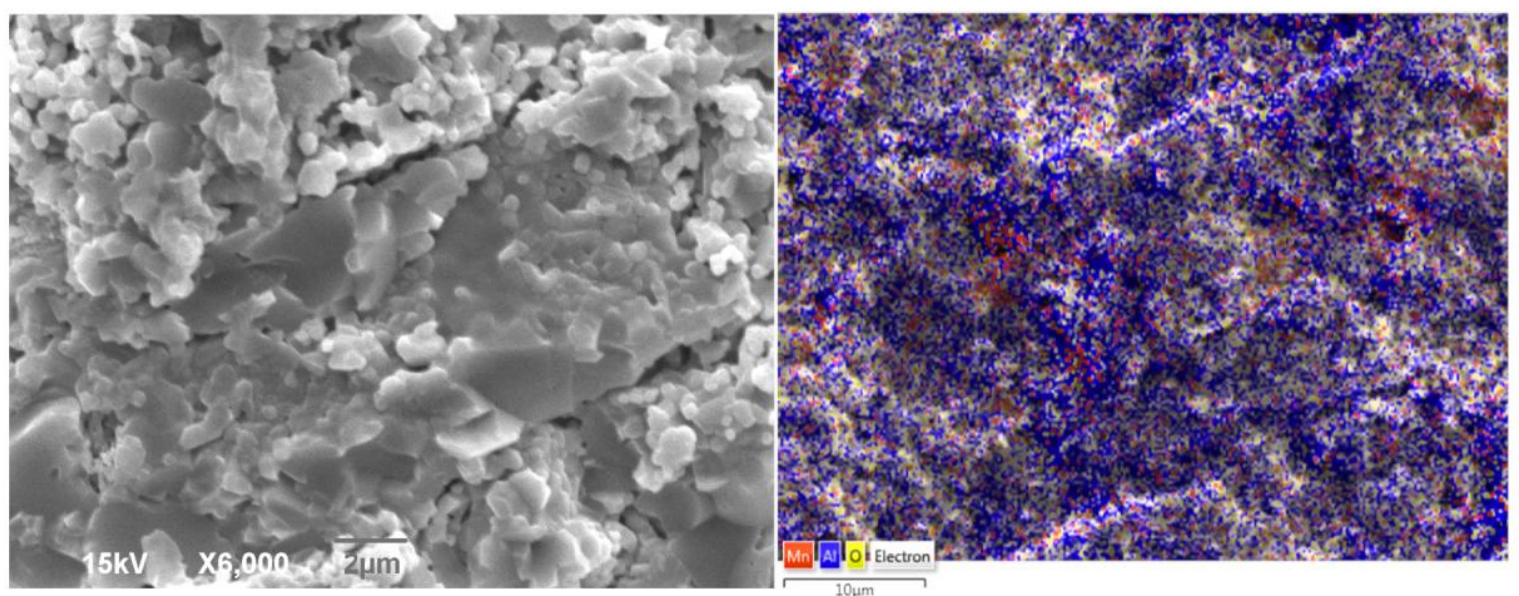

Fig.8.c 


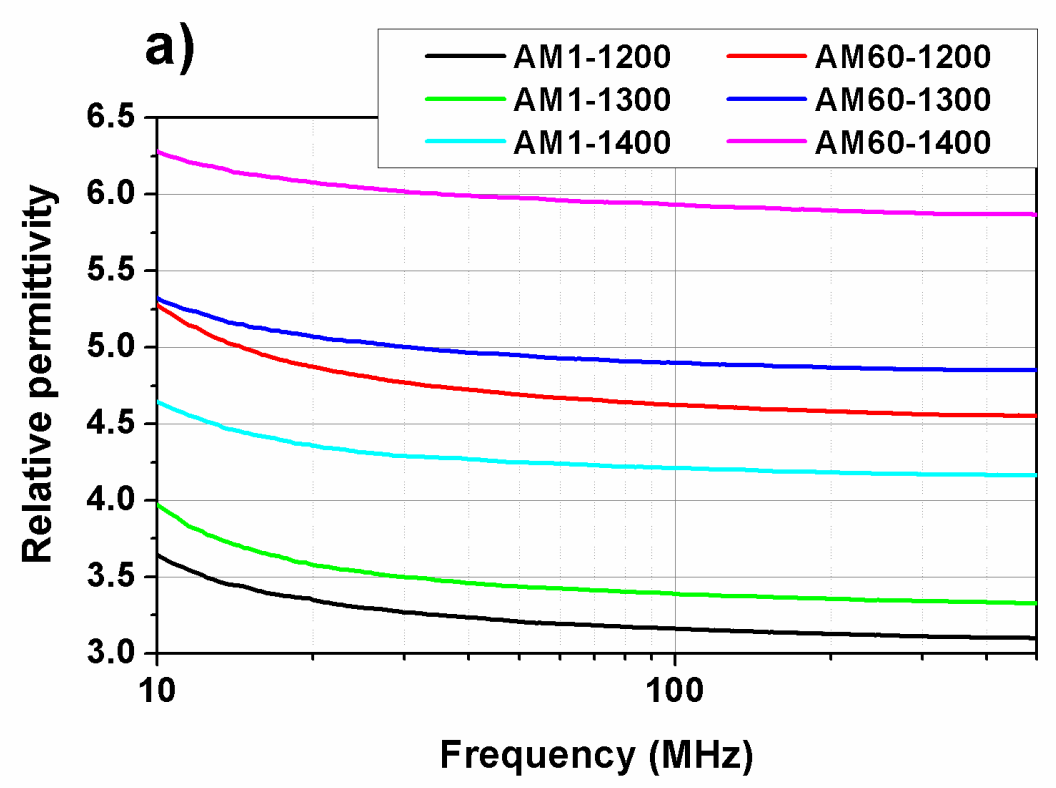

b)

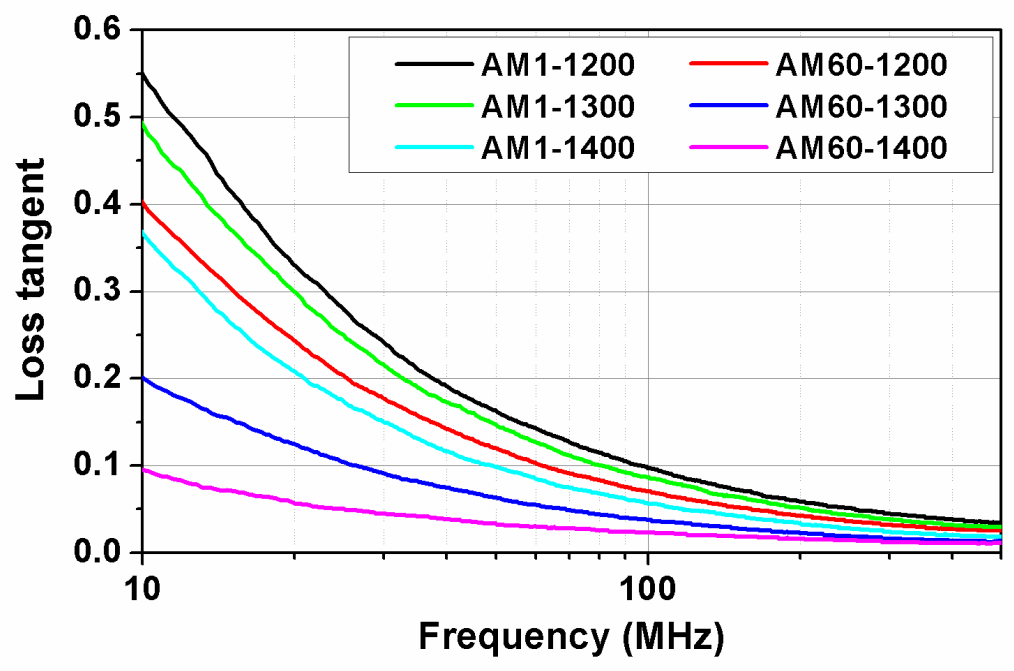

Fig.9.

\section{Figure captions:}

Fig. 1. Sketch of the test fixture for measurement of dielectric parameters of sintered samples.

Fig. 2. XRD patterns of alumina doped with 1 wt. $\% \mathrm{Mn}_{2} \mathrm{O}_{3}$ mixtures: non-activated (AM1) and mechanically activated (AM60) Error! Bookmark not defined.. [used with permission of editor] Fig. 3. Particle size distribution for AM1 and AM60.

Fig. 4. SEM of: a) AM1 and b) AM60. 
Fig. 5. DTA and TGA curves and dTG inlay images for: a) homogenized (AM1) and b) ball-milled (AM60) powder.

Fig. 6. a) XRD patterns of non-activated samples sintered at $1200-1400{ }^{\circ} \mathrm{C}$ (AM1-1200, AM1-1300, AM1-1400) and b) XRD patterns of activated samples sintered at 1200-1400 ${ }^{\circ} \mathrm{C}$ (AM60-1200, AM60-1300, AM60-1400).

Fig. 7. SEM and EDS pictures of non-activated and sintered samples a) AM1-1200, b) AM1-1300, and c) AM1-1400.

Fig. 8. SEM and EDS pictures of activated and sintered samples a) AM60-1200, b) AM60-1300, c) AM60-1400.

Fig. 9. Measured a) real part of relative permittivity and b) loss tangent, as a function of frequency, for sintered samples. 